\title{
The analysis of future flood risk in the UK using the Future Flood Explorer
}

\author{
Paul Sayers ${ }^{1, \mathrm{a}}$ Matt Horritt ${ }^{2}$, Edmund Penning-Rowsel1 ${ }^{3}$, Andrew McKenzie ${ }^{4}$, David Thompson ${ }^{5}$ \\ ${ }^{1}$ Partner, Sayers and Partners, Fellow, Environmental Change Institute, University of Oxford. Email: paul.sayers@sayersandpartners.co.uk \\ ${ }^{2}$ Horritt Consulting \\ ${ }^{3}$ Flood Hazard Research Centre, Middlesex University \\ ${ }^{4}$ British Geological Survey, England \\ ${ }^{5}$ Committee on Climate Change, London
}

\begin{abstract}
The assessment of future flood risk presented considers three climate change scenarios $\left(\mathrm{a} 2^{\circ} \mathrm{C}\right.$ and $4^{\circ} \mathrm{C}$ change in Global Mean Temperature by the 2050s and 2080s and a more extreme, but plausible future, the so-called $\mathrm{H}++$ future), and three population growth projections (low, high and no growth). The analysis covers the whole of the UK (England, Wales, Scotland and Northern Ireland) and the risks associated with coastal, fluvial, surface water and groundwater flooding. Eight individual Adaptation Measures (including spatial planning, flood defence, catchment storage) are used to construct five Adaptation Scenarios (including enhanced and reduced levels of adaptation ambition in comparison to present day). Future flood risks for a range of climate, population and adaptation combinations are assessed using the UK Future Flood Explorer. The analysis highlights that significant increases in flood risk are projected to occur as early as the 2020s; a finding that reinforces the need for urgent action. The analysis also highlights that to manage risk effectively under a 2 or $4^{\circ} \mathrm{C}$ future an enhanced whole system approach to adaptation is needed. This will require action by a broad range of stakeholders, from national level down to individual households and businesses.
\end{abstract}

\section{Background}

The 2008 Climate Change Act established the UK Committee on Climate Change (CCC) and its statutory role to provide independent evidence on current and future risks facing the UK from climate change and progress being made in adapting to future risks (Figure 1). The evidence is provided by the CCC directly to Parliament. The Climate Change Risk Assessment (CCRA) provides the evidence used by the CCC to help guide the UK Government's priorities through the National Adaptation Programme and more local adaptation actions.

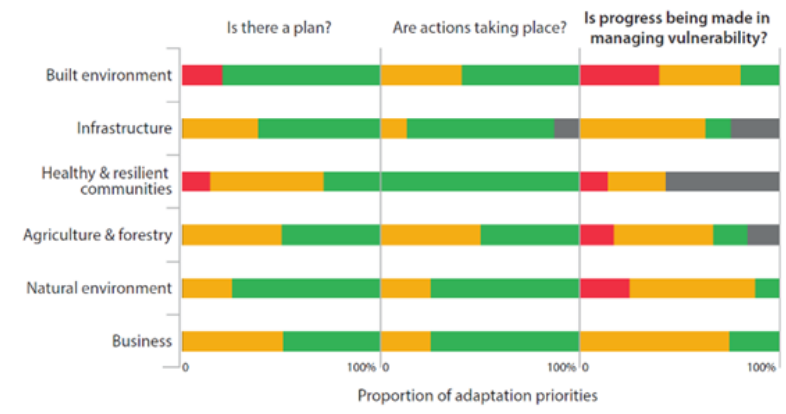

Green: plans are in place, actions are being delivered, progress is being made

adaptation priority has been partially addressed, some evidence of progress in some areas plans and policies, delivery of actions, or progress in addressing vulnerabilities, are lacking Grey: insufficient evidence to form a judgement

Figure 1 Review of progress in preparing for climate change across multiple sectors in the UK $(A S C, 2015)$
The focus on this paper is the approach to assessment of future flood risks undertaken as part of this process. The assessment, incorporates all sources of flooding (including fluvial, coastal, surface water and groundwater) and the impacts on households, communities, businesses and infrastructure operators across the whole of the UK through to the 2080s. The Future Flood Explorer (FFE), an innovative emulation model, is used to represent the present and future flood risk system (including the storm loading, the performance of flood defences and impacts). The high computational efficiency of the FFE enables a consistent assessment of food risk across England, Wales, Scotland and Northern Ireland under multiple scenarios of change, including: (i) two climate change projections $\left(2^{\circ} \mathrm{C}\right.$ and $4^{\circ} \mathrm{C}$ rise in Global Mean Temperature) and a more extreme, but plausible, H++ change scenario (Met Office, 2015); (ii) low and high population projections; and, (iii) five alternative adaptation policy scenarios (including a continuation of current levels of adaptation as well as higher and lower levels of adaptation ambition).

\section{Approach to the analysis of future risk}

The analysis presented here assesses the impact of climate change and population growth on future flood risk (to the 2080s) and the opportunity to manage these risks through adaptation. The supporting analysis is

\footnotetext{
${ }^{a}$ Corresponding author: mike.steel@environment-agency.gov.uk
} 
credible at the chosen scales of aggregation (UK wide, national and regional); uses data that are recognisable to lead authorities; is consistently applied across the whole of the UK; assesses all sources of flood risk (fluvial, coastal, surface water and groundwater); defines a range of future adaptation scenarios and assesses their ability to manage future flood risk; and considers combined scenarios of climate change, population growth and adaptation to enable a meaningful comparison between risks now and in the future.

\subsection{Flood sources considered}

Four sources of flooding are considered within the FFE:

- River: Flooding from a watercourse when water from an established river or drainage channel spills onto the floodplain (referred to here as fluvial flooding).

- Coastal: Flooding from the sea when tidal surge, wave action or a combination of tidal surge and waves overtop or overflow the shoreline boundary.

- Pluvial: Flooding directly from a rainfall event prior to the generated run-off reaching an established river or drainage channel (typically, and somewhat confusingly, called surface water flooding in the UK and, hence referred to surface water in this paper)).

- Groundwater: Flooding from aquifers (clearwater flooding) and permeable superficial deposits (PSD) on fluvial floodplains.

\subsection{Future changes in drivers of risk}

The analysis considers both exogenous change (i.e. changes outside of the influence of flood risk management policy) and endogenous change (i.e. changes to the flooding system that are either directly controlled or strongly influenced through policies and actions that modify flood risk). These changes form the basis of alternative futures explored and are introduced below.

\section{Exogenous change: Population and climate change:} Two drivers of exogenous change (i.e. changes outside of the influence of flood risk management policy) are considered; population growth and climate change. Population projections are used to estimate the number of people and residential property that may be exposed to flooding in the future. Three population growth scenarios are used. The first two (a low growth projection, representing a $20 \%$ increase in population of the UK by $2080 \mathrm{~s}$ and high population growth projection, representing a $53 \%$ increase in population of the UK by 2080s) are taken from the Office of National Statistics (ONS) projections (Figure 2). A third 'no growth' projection is also used. Two climate change projections are considered. These reflect the standard approach set out by the CCC to ensure consistency in the climate change projections adopted in CCRA and include a $2^{\circ} \mathrm{C}$ and $4^{\circ} \mathrm{C}$ rise in Global Mean Temperature (GMT) by 2080 (from the 1961-90 baseline as used in UKCP09). A
High $++(\mathrm{H}++)$ scenario is also used. The $\mathrm{H}++$ scenario is not related to a particular change in GMT but adopted as a credible, but high-end, change scenario.
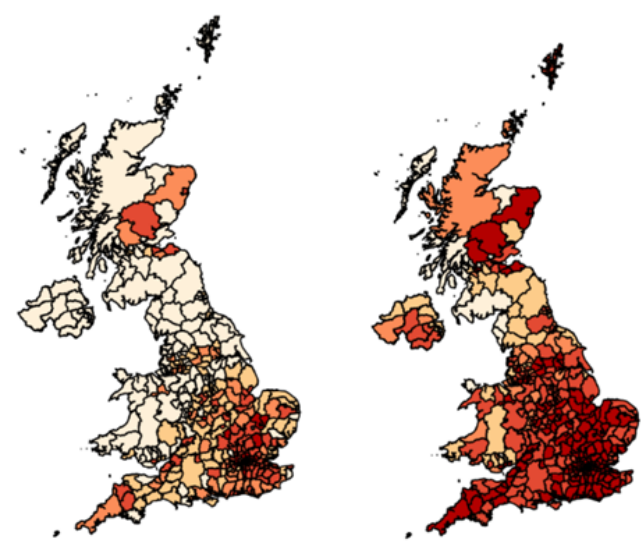

$\%$ Change $2012-2086$

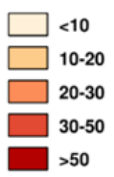

Figure 2 Low (left) and high (right) population growth scenarios (HR Wallingford, 2015)

Endogenous change: Purposeful adaptations: Endogenous change refers to changes to the flooding system that are either directly controlled or strongly influenced through policies and actions that modify flood risk. In this context a broad range of individual Adaptation Measures (AMs) are considered including those that:

- Manage the probability of flooding: By improving traditional flood defences, managing flood flows (such as rural and urban storage and run-off management) or realigning the coast to improve the Standard of Protection (SoP) afforded by a defence.

- Manage exposure to flooding: By limiting the impact of new development on flood risk.

- Manage the vulnerability of those exposed to flooding: By encouraging individuals and organisations to improve the flood resistance and resilience of their properties/assets or improving forecasting and warning to enable more effective action to be taken.

The degree of adaptation, however, crucially depends upon the interpretation and implementation of these policies rather than the policies themselves. In recognition of this, each adaptation policy has been considered in the context of three levels of adaptation:

- A continuation of current levels of adaptation (CLA): Flood risk management policies continue to be implemented as effectively as experienced in the recent past (i.e. achieving the same outcomes as in recent years).

- A high(er) level of adaptation: Flood risk management policies are more effectively implemented than in the recent past. 
- A low(er) level of adaptation: Flood risk management policies are less effectively implemented than in the recent past.

Many studies have confirmed that flood risk is best managed through a portfolio of measures implemented through a continuous processes of adjustment (Sayers et al, 2002, Evans et al 2004a\&b, Sayers et al., 2014). This is reflected in much of the UK flood risk management policy (e.g. HM Treasury Green Book (2003); Making Space for Water (Defra 2005); Working with Natural Processes (Environment Agency, 2010, 2014b); Delivering Sustainable Flood Risk Management (Scottish Government, 2011)). The individual Adaptation Measures (introduced above) have been used to create six alternative Adaptation Scenarios with a varying level of adaptation ambition and focus. These are shown in Figure 3 and summarised below.

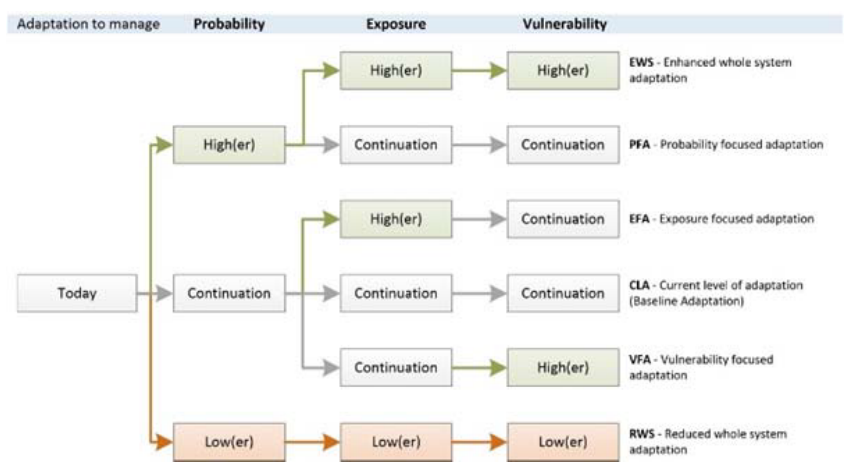

Figure 3 Alternative Adaptation Scenarios (Sayers et al, 2015a)

- Baseline adaptation: Continuation of Current Level of Adaptation (CLA): Under the CLA scenario all individual Adaptation Measures continue to be implemented as in recent years.

- Enhanced 'whole system' adaptation (EWS): Adaptation is high(er) than the current level across all individual Adaptation Measures (including those to manage probability, exposure and vulnerability). Under the EWS Adaptation Scenario investment in flood defences increases and land use planning policy is more rigorous in restricting inappropriate development. Experience of flooding together with the increasing cost of flood insurance encourages the take-up of Receptor Level Protection at a greater rate than in recent years. Flood forecasting and warning systems develop with increased levels of sophistication, targeting those at risk more accurately than has been possible to date.

- Probability focused adaptation (PFA): Enhanced effort is directed towards the management of the probability of flooding, with high(er) levels of adaptation in both traditional flood defences as well as responses that work with natural processes to manage catchment flows, urban run-off and coastal realignment. Exposure and vulnerability focused measures such as Receptor Level Protection (RLP), land use planning and forecasting and warning continue to be implemented at the current level of adaptation.

- Exposure focused adaptation (EFA): Land use planning is strengthened and experiences a high(er) level of adaptation in comparison to present day. This reflects increased awareness of flooding and a concern to limit development in flood-prone areas through more rigorous regulation of planning decisions. All other measures continue to be implemented at the current level of adaptation.

- Vulnerability focused adaptation (VFA): Reducing the vulnerability of the people and infrastructure exposed to flooding has an increased focus, with high(er) levels of adaptation in this regard. There is a greater emphasis on individuals, organisations and communities taking action to reduce their vulnerability through receptor level protection. There is also a greater demand for flood forecasting and warning arrangements and these improve. All other measures continue to be implemented at the current level of adaptation.

- Reduced 'whole system' adaptation (RWS): The adaptation effort as a whole reduces. All Adaptation Measures are implemented at a low(er) level than the current levels of adaptation. Investment in traditional defences reduces (reflecting a reduction in the willingness to pay for defences from national tax revenues as flooding is increasingly seen as less of a national risk and more of a local one, but local funding fails to replace centralized investments). There is little take up of innovative catchment-based or urban run-off measures occurs, spatial planning becomes less rigorous (resulting in new development on the floodplain than currently is the case), and flood forecasting and warning systems and receptor level protection see low(er) levels of effectiveness and performance.

\subsection{Supporting assessment method}

The number of adaptation, population and climate scenarios, and the epochs, sources and risk metrics considered, mean that traditional modelling approaches are too computationally intensive to explore all combinations (a challenge recognised in Kwakkel et al, 2013). Instead, the approach used builds upon lessons from past national scale studies undertaken in the UK (e.g. Evans et al, 2004a\&b) and insights from international studies (e.g. Klijn, et al, 2004 and 2014, Bouwer, et al. 2010) to allow a rapid evaluation of the effects of climate and population change and adaptation using the UK Future Flood Explorer (FFE).

The UK FFE provides an emulation of the UK flood risk system that embeds nationally recognized source, pathway and receptor data from across the UK to construct an emulation of the present day flood risk system and to explore the future change in flood risk. It is fast to run and capable of exploring the impact of future 
change on a range of risk metrics. The FFE relies upon nationally available datasets from each country and provides a consistent UK-wide view of changes in flood risk arising from all sources. The quick run time of the FFE allows the alternative epochs, climate change futures and alternative Adaptation Scenarios to be assessed with limited runtime overhead.

The real world flood risk system is represented spatially within the FFE using Calculation Areas determined as follows:

- Within river and coastal floodplains: Calculation Areas are determined through consideration of the river network, boundaries of the floodplain and the coastline.

- Outside of the fluvial or coastal floodplains: Calculation Areas are created by sub-dividing the land surface into $1 \mathrm{kmx} 1 \mathrm{~km}$ squares.

A schematisation of the Calculation Areas for a small region is shown in Figure 4Figure.

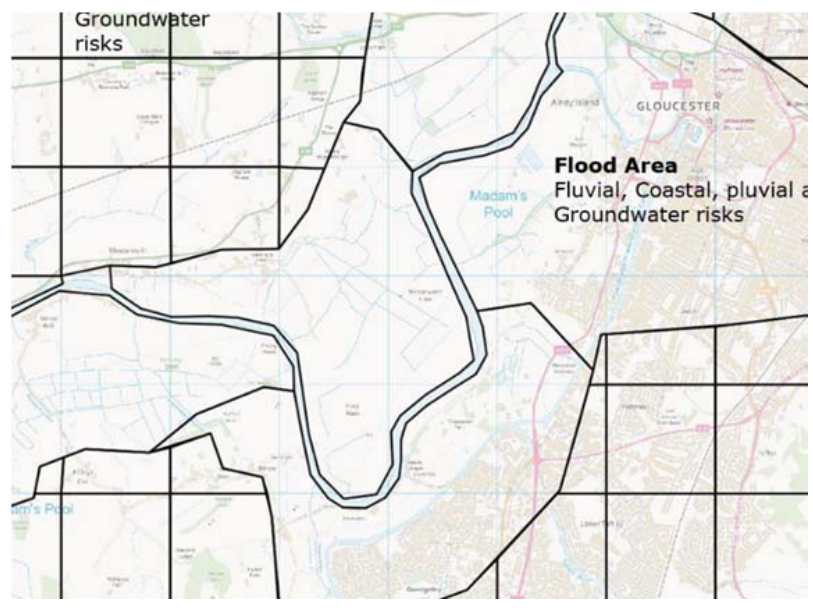

Figure 4 Calculation Areas aggregate nationally available flood information for use in the FFE

An Impact Curve (relating the return period of a flood event to the damage that would be incurred) is then generated for each Calculation Area (Figure 5) based upon nationally available input data and results from the available flood modelling. The Impact Curves are then used to "look up" the impacts for any given return period and all risk metrics of interest (this is the essence of the emulation process). This process enables annual average damages to be assessed (by looking up damages associated with multiple return periods). It also enables the influence of climate and population change as well as adaptations to be assessed by making modifications to the Impact Curves (for example representing climate change by moving the impact curve along the return-period axis).

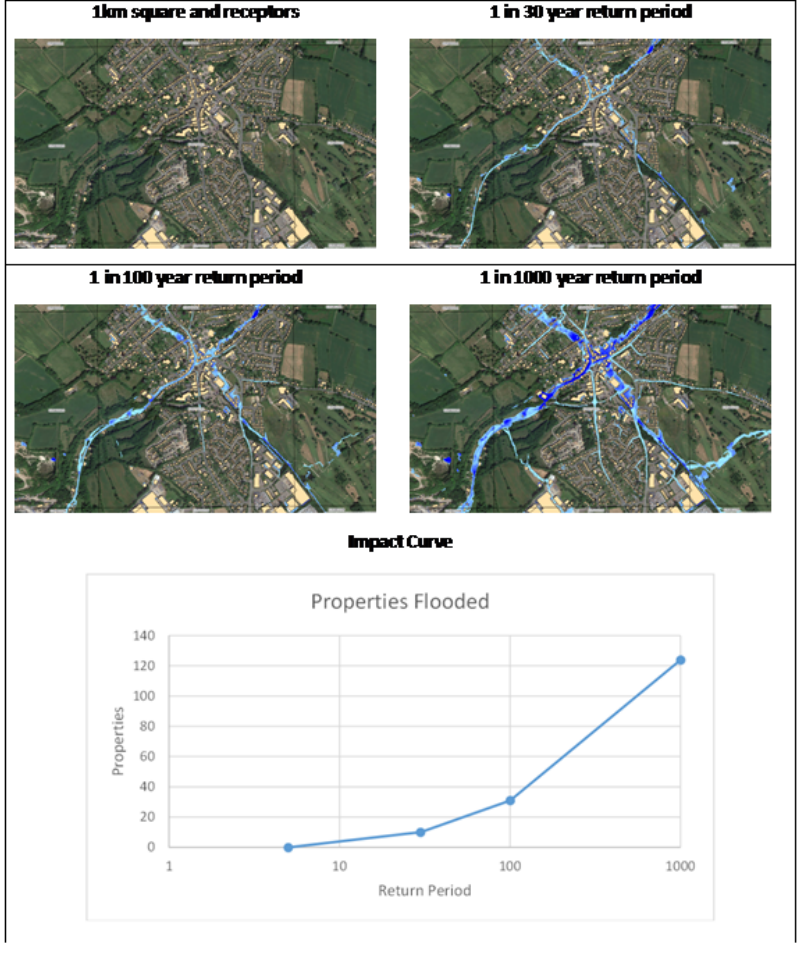

Figure 5 Developing an Impact Curve with the Future Flood Explorer: A hypothetical example for surface water (pluvial) flooding

The flexibility of the UK FFE enables multiple futures to be explored and compared, and for the first time, the impact of adaptation, climate change and population drivers to be investigated separately and in combination. A detailed description of the FFE is provided in Sayers et al, $2015 b$.

\section{Insights into how future flood risks may change}

The following sections provide a summary overview of the most important findings from the analysis. The underlying numbers and more detailed descriptions can be found in Sayers et al, 2015a.

How might risk change in the future if we continue to manage flood risk as present? If current levels of adaptation continue Expected Annual Damages (EAD) are projected to increase significantly by 2080 s. The projected increases are $50 \%$ under the $2^{\circ} \mathrm{C}$ climate change projection, $150 \%$ under $4^{\circ} \mathrm{C}$ climate change projection, and six fold under the $\mathrm{H}++$ scenario. When projections of population growth are included the risks increase further.

Proportional increases in risk at a UK scale are broadly reflected in increases for constituent countries. Within each country there are significant regional variations (Figure 6), showing EAD assuming current levels of 
adaptation, with risk increases in some regions three times greater than in others.

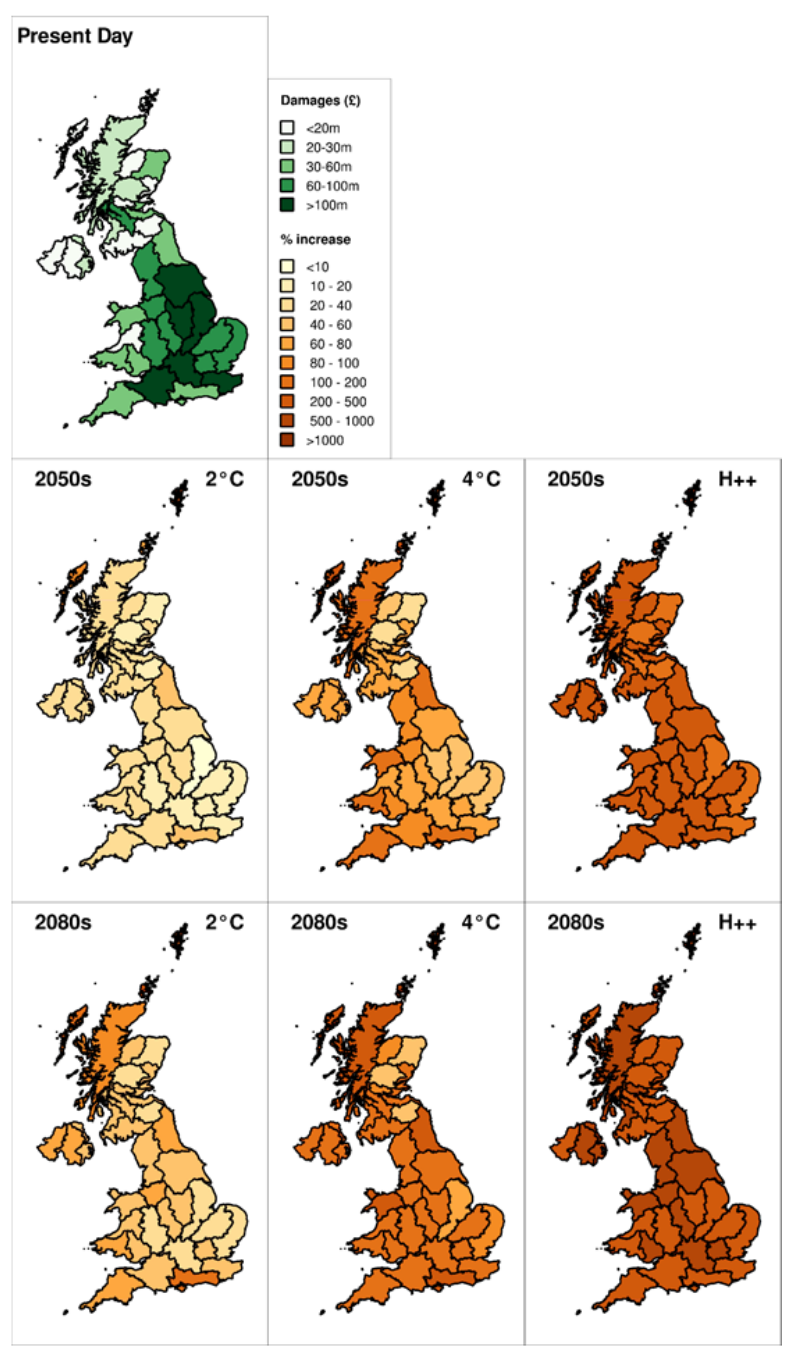

Figure 6 Future changes in Expected Annual Damages given a continuation of current levels of adaptation and low population growth (Sayers et al, 2015a)

What is the relative importance of climate change and population growth? Climate change and population growth are both important drivers of increasing risk (Table 1). For example, the $2^{\circ} \mathrm{C}$ climate change projection results in a greater increase in flood risk (in terms of Expected Annual Damages) than population growth alone, even assuming high growth.

Table 1 Relative effects of climate change and population growth

\begin{tabular}{|l|l|l|l|l|}
\hline \multicolumn{2}{|l|}{$\begin{array}{l}\text { Climate scenario and indicator risk } \\
\text { metric }\end{array}$} & $\begin{array}{l}\text { CLA } \\
\mathbf{2 0 8 0 s} \\
\text { No } \\
\text { population } \\
\text { growth }\end{array}$ & $\begin{array}{l}\text { CLA } \\
\mathbf{2 0 8 0 s} \\
\text { Low } \\
\text { population } \\
\text { growth }\end{array}$ & $\begin{array}{l}\text { CLA } \\
\mathbf{2 0 8 0 s} \\
\text { High } \\
\text { population } \\
\text { growth }\end{array}$ \\
\hline \multirow{2}{*}{$2^{\circ} \mathrm{C}$} & $\begin{array}{l}\text { Residential Properties at risk of } \\
\text { flooding more frequently than 1:75 } \\
\text { years (on average) }\end{array}$ & $+40 \%$ & $+73 \%$ & $+140 \%$ \\
\cline { 2 - 5 } & $\begin{array}{l}\text { Expected Annual Damages (EAD) } \\
\text { - Residential properties }\end{array}$ & $+50 \%$ & $+58 \%$ & $+63 \%$ \\
\hline \multirow{2}{*}{$4^{\circ} \mathrm{C}$} & $\begin{array}{l}\text { Residential Properties at risk of } \\
\text { flooding more frequently than 1:75 } \\
\text { years (on average) }\end{array}$ & $+93 \%$ & $+140 \%$ & $+230 \%$ \\
\cline { 2 - 5 } & $\begin{array}{l}\text { Expected Annual Damages (EAD) } \\
- \text { Residential properties }\end{array}$ & $+150 \%$ & $+160 \%$ & $+160 \%$ \\
\hline
\end{tabular}

Which flood sources are most important for risk today and in the future? The most significant source of flooding today (based analysis of the underlying data provided by the lead authorities in each country) is fluvial (river), contributing $£ 560 \mathrm{~m}(40 \%)$ of total UK EAD. Coastal flooding contributes $£ 320 \mathrm{~m}(24 \%)$, excess rainfall $£ 260 \mathrm{~m}(20 \%)$ and groundwater $£ 210 \mathrm{~m}(16 \%)$. In the future all of these sources are projected to increase risk (Figure 7). Under the $\mathrm{H}++$ scenario fluvial risk increases more than for the other sources.

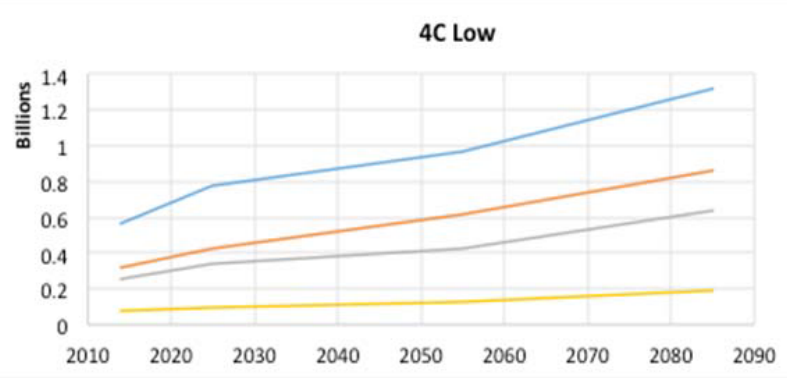

Top line: Fluvial flooding, $2^{\text {nd }}$ line: Coastal flooding; $3^{\text {rd }}$ line: Surface water flooding; Bottom line: Groundwater

Figure 7 Expected Annual (direct) Damages (EAD) by flood source: Example shown $4^{\circ} \mathrm{C}$ low population growth given a continuation of current levels of adaptation (Sayers et al, 2015a)

Future change in groundwater flooding is dominated by flooding from permeable superficial deposits (PSD). PSD flooding responds to changes in the frequency of fluvial flooding and hence reflect changes in the frequency of fluvial flooding. Groundwater flooding from both chalk and non-chalk aquifers (so-called Clearwater flooding) makes a small contribution to present and future flood risk in England and Wales and no contribution in either Scotland and Northern Ireland (although there may be localised issues).

What are the implications of sea levels continuing to rise? Wave conditions around much of the UK coast are limited in size by the nearshore water depth. Because of this, relative Sea Level Rise (rSLR) has a dominant influence on coastal flooding, (increasing both wave driven overtopping, the chance of a breach probability 
and, in more extreme climate change projections, tidal overflow. A $0.5 \mathrm{~m}$ sea level rise (approximately equivalent to a $4^{\circ} \mathrm{C}$ increase in GMT by the 2080 s) would make some $200 \mathrm{~km}$ of coastal defences $(20 \%$ of the total length in England) highly susceptible to failure (Figure 8). Significant additional investment would be required to sustain these defences in their current location. A 'whatif' analysis suggests that if these defences were lost, the inundated area during a 1:200 year return period coastal surge would significantly increase, resulting in an additional 310,000 properties being exposed to coastal flooding when compared to the same event occurring under current sea levels. A $1.5 \mathrm{~m}$ rise in mean sea level would affect $300 \mathrm{~km}$ of defences and potentially 540,000 properties.

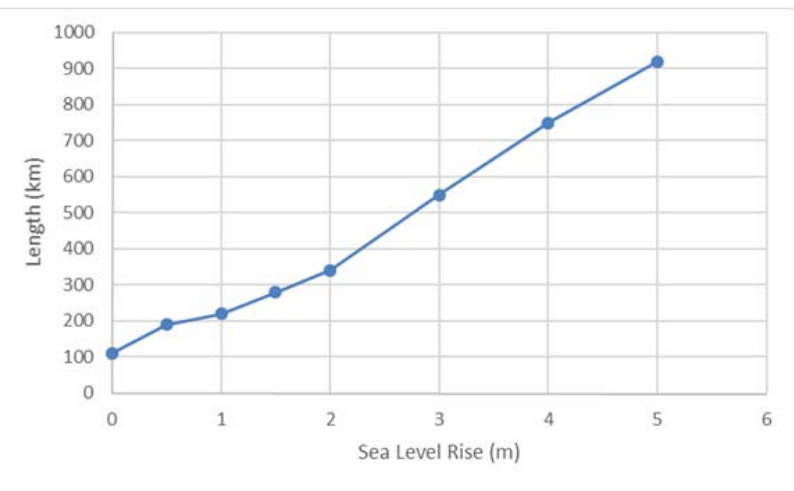

Figure 8 Length of coastal defences that are likely to become highly vulnerable to failure as sea levels rise in England (Sayers et al, 2015a)

What are the main impacts of future flooding? The number of residential properties exposed to flooding more frequently than 1:75 years (on average) increases significantly in all futures; increasing from 860,000 today to 1.2 million (a $40 \%$ increase) by the 2080 s under a $2^{\circ} \mathrm{C}$ increase in GMT, and to 1.7 million (a 93\% increase) under $4^{\circ} \mathrm{C}$. Both of these estimates assume no population growth and adaptation continuing at current levels.

The area of Special Protection Areas, Special Areas of Conservation and Ramsar sites exposed to flooding more frequently than $1: 75$ (on average) increases by $25 \%$ and $44 \%$ for $2^{\circ} \mathrm{C}$ and $4^{\circ} \mathrm{C}$ respectively by the 2080 s. The area of Best and Most Versatile (BMV) agricultural land exposed to frequent flooding (more frequent than 1:75 year return period, on average) increases by $32 \%$ and $65 \%$ under these climate projections.

Impacts on social infrastructure are similar to those seen for residential property. By the 2080s the number of care homes located in the highest flood probability category increase by $48 \%$ and $140 \%$; schools by $32 \%$ and $95 \%$; emergency services sites by $36 \%$ and $100 \%$; hospitals by $23 \%$ and $68 \%$; and GPs surgeries by $46 \%$ and $140 \%$ for $2^{\circ} \mathrm{C}$ and $4^{\circ} \mathrm{C}$ respectively, assuming current levels of adaptation are continued and no population growth.
The increases in Expected Annual Damages are greater than increases in numbers of properties in areas most likely to be flooded. Present day Expected Annual Damages are estimated to be approximately $£ 1.1$ bn (for the UK as a whole, excluding groundwater) and consistent with existing estimates from each country (although these are controversial, cf. Penning-Rowsell (2015)). The analysis presented here estimates that by the 2080s present day risks increase by $55 \%$ (under $2^{\circ} \mathrm{C}$ climate change projection) and by $154 \%$ (under $4^{\circ} \mathrm{C}$ climate change projection), assuming no population growth and continuing adaptation at current levels. Under the high growth population projection, these figures increase to $£ 1.8 \mathrm{bn}$ and $£ 2.9 \mathrm{bn}$ for $2^{\circ} \mathrm{C}$ and $4^{\circ} \mathrm{C}$ respectively.

How does the number of people at risk change, including in deprived communities? The total number of people living in properties exposed to flooding more frequently than 1:75 years (on average) increases from 1.8 milllion in the present day to 2.5 million (an increase of $41 \%$ ) under $2^{\circ} \mathrm{C}$ climate change projection and 3.5 million (an increase of $98 \%$ ) under $4^{\circ} \mathrm{C}$ climate change projection by the 2080 s, assuming current levels of adaptation are continued and no population growth (Figure 9). People living in properties located within the UK's most deprived communities face even higher increases in risk. The number of people in these areas exposed to flooding more frequently than 1:75 years (on average) increases by $48 \%$ and $110 \%$ under $2^{\circ} \mathrm{C}$ and $4{ }^{\circ} \mathrm{C}$ respectively.

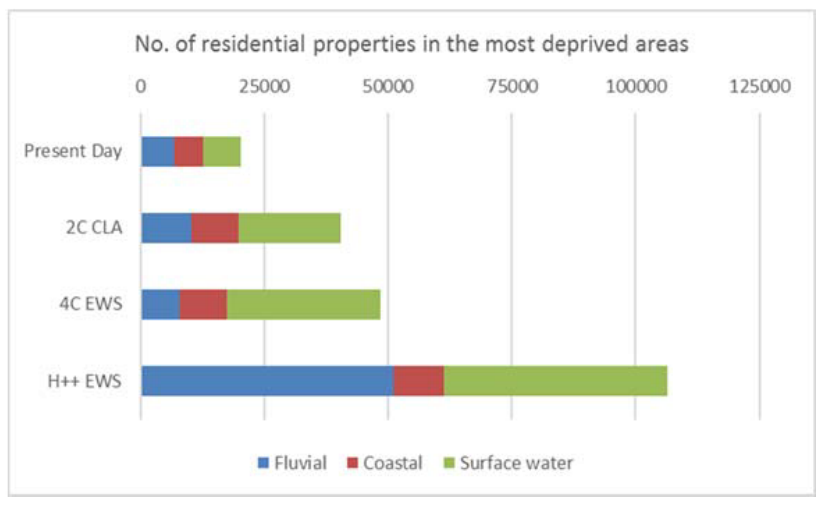

Figure 9 The contribution of different sources of flood (fluvial/coastal/surface water) to very frequent flooding (return period between 1:10 and 1:30) in the most deprived areas (Sayers et al, 2016)

How might risk to national infrastructure change? Infrastructure assets will be subject to significant increases in risk; with the number of sites exposed to the highest chance of flooding (i.e. more frequently that 1:75 years on average) increasing by $30 \%$ (under $2^{\circ} \mathrm{C}$ climate change projection) and $200 \%\left(4^{\circ} \mathrm{C}\right.$ climate change projection) by the 2080 s. Local actions currently being taken to protect infrastructure assets (e.g. for electricity substations) to a 1:200 year return period standard are effective in reducing risk for the 2020 s and 2050s; but 
protection to an even higher standard would be required to cope with climate changes anticipated for the 2080s.

Effects of climate change on transport infrastructure are also significant; the length of railway line located in areas exposed to flooding more frequently than 1:75 years (on average) increases in the 2080 s by $53 \%$ and $160 \%$; the length of major roads by $41 \%$ and $120 \%$; the number of railway stations by $10 \%$ and $28 \%$ for $2{ }^{\circ} \mathrm{C}$ and $4^{\circ} \mathrm{C}$ respectively.

By how much can adaptation offset the projected increases in risk? Current levels of adaptation can offset a significant proportion of the projected increase in risk (30-50\% of the EAD increase arising from climate change and population growth), but will not be sufficient to completely offset all of the projected increases under either a $2^{\circ} \mathrm{C}$ or $4^{\circ} \mathrm{C}$ climate change projection. Under more extreme climate change current levels of adaptation would do little to prevent a significant increase in risk.

Delivering enhanced levels of adaptation can offset all the increase in risk under the $2^{\circ} \mathrm{C}$ climate change and low population growth projection, and almost all the increase under a $2^{\circ} \mathrm{C}$ climate change and high population growth projection. Enhanced levels of adaptation can offset $70 \%$ of the increase in risk associated with the $4{ }^{\circ} \mathrm{C}$ climate change and high growth projection. Achieving this level of adaptation is, however, ambitious and will require concerted action across all aspects of policy and implementation. It is also likely to require significant additional investment (both public and private), although the amount required was not assessed. However, under a $4^{\circ} \mathrm{C}$ rise, even an enhanced level of adaptation will not be sufficient to completely offset the increase in flood risk from a combination of climate change and population growth.

What types of adaptation measures are most effective at reducing risk? The most effective Adaptation Measures (considered here) are those that reduce the probability of flooding. This includes improving defences, managed realignment on the coast, catchment management and urban runoff management through sustainable drainage systems (SuDS).

Spatial planning and building codes are already very effective at reducing the risk to new build properties within the coastal and fluvial floodplain (less so in areas prone to surface water (e.g. pluvial) or groundwater flooding) and remain an important component in all future Adaptation Scenarios. The potential for perverse outcomes is highlighted where development is relocated away from one source of flooding (i.e. fluvial or coastal) into areas subject to either surface water (e.g. pluvial) or groundwater flooding.
Adaptations that focus solely on reducing exposure and vulnerability are less able to influence future risks than those providing a more comprehensive whole system adaptation response. This is because the estimated increase in flood risk is dominated by the vulnerability of the existing stock of properties. Even under the highest level of adaptation considered here, take up of receptor level protection measures amongst existing residential and non-residential properties owners is limited (50\% by 2080 s in areas with a high chance of flooding).

\section{Conclusions}

The innovative analysis provided by the Future Flood Explorer has for the first time enabled a consistent UK wide assessment of future flood risk taking account of four sources of flooding, population growth and adaptation. The FFE has been shown to be a practical and credible approach that is fast to run enabling multiple futures to be explored.

The analysis highlights that properties that are currently located within the areas of the fluvial or coastal floodplain with a low standard of protection (i.e. less than 1:75 years) are projected to experience significant increases in risk. The assumption made here (in line with findings from the Environment Agency's Long Term Investment Scenarios, 2014) is that the national investment case for providing community scale defences to these areas is limited. The significant increase in risk appears under all Adaptation Scenarios, reflecting the difficulty of retrofitting property or community level protection.

The analysis also highlights that to manage risk effectively under a 2 or $4^{\circ} \mathrm{C}$ future an enhanced whole system approach to adaptation is needed. This will require action by a broad range of stakeholders, from national level down to individual households and businesses.

Perhaps most importantly the significant increases in flood risk are projected to occur as early as the 2020s; a finding that reinforces the need for urgent action. For example, the number of residential properties exposed to flooding more frequently than 1:75 years (on average) is predicted to increase by $20 \%$ by the 2020 s under the scenario which gives a $4^{\circ} \mathrm{C}$ rise in GMT by the 2080s; EAD is also predicted to increase by $30 \%$. This reinforces evidence from recent climate attribution studies that suggest the influence of climate change on flooding, and hence flood risk, may already be detectable and should be anticipated. The need for early adaptation also reflects the long lead time required to implement policy change and the long lived nature of the decisions made today that influence future risk. 


\section{References}

ASC (2015). Progress in preparing for climate change 2015 Report to Parliament Committee on Climate Change June 2015. https://www.theccc.org.uk/wpcontent/uploads/2015/06/6.736 CCC ASC AdaptationProgress-Report 2015 FINAL WEB 250615 RFS.pdf

Bouwer, L.M., Bubeck, P. and Aerts, J.C., 2010. Changes in future flood risk due to climate and development in a Dutch polder area. Global Environmental Change, 20(3), pp.463-471.

Evans, E., Ashley, R., Hall, J., Penning-Rowsell, E., Saul, A., Sayers, P., Watkinson, A. (2004a). Foresight Future Flooding, Scientific Summary: Volume 2: Managing future risks. Office of Science and Technology, London.

Evans, E., Ashley, R., Hall, J., Penning-Rowsell, E., Saul, A., Sayers, P., Watkinson, A. (2004b). Foresight Future Flooding, Scientific Summary: Volume 1: Future risks and their drivers. Office of Science and Technology, London.

DEFRA (2005). Making Space for Water: Taking Forward a New Government Strategy for Flood and Coastal Erosion. First Government Response to the Autumn 2004 Making Space for Water Consultation Exercise. London: Department of the Environment, Food and Rural Affairs.

Environment Agency (2010). Working with natural processes to manage flood and coastal erosion risk. London: Environment Agency.

HM Treasury (2003). The Green Book: Appraisal and Evaluation in Central Government.

HR Wallingford (2015) Update analysis of the number of properties located in areas at risk of flooding and coastal erosion in England. A HR Wallingford report completed from the ASC.

Klijn, F., van Buuren, M. and van Rooij, S.A., 2004. Flood-risk management strategies for an uncertain future: living with Rhine river floods in the Netherlands?. AMBIO: A Journal of the Human Environment, 33(3), pp.141-147.

Klijn, F., de Bruijn, K.M., Knoop, J. and Kwadijk, J., 2012. Assessment of the Netherlands' flood risk management policy under global change. Ambio, 41(2), pp.180-192.
Kwakkel, J.H. and Pruyt, E., 2013. Exploratory Modeling and Analysis, an approach for model-based foresight under deep uncertainty. Technological Forecasting and Social Change, 80(3), pp.419-431.

Met Office (2015). Developing $\mathrm{H}++$ climate change scenarios for heatwaves, droughts, floods, windstorms and cold snaps. A report for the ASC, London. https://www.theccc.org.uk/publication/met-office-for-theasc-developing-h-climate-change-scenarios/ Accessed May 2016Penning-Rowsell, E.C. (2015). A realistic assessment of fluvial and coastal flood risk in England and Wales. Transactions of the Institute of British Geographers 40(1) 44-61.

Sayers PB; Hall JW; Meadowcroft IC (2002). Towards risk-based flood hazard management in the UK. Civil Engineering 2002, 150(5), 36-42.

Sayers, P. B., Galloway, G., Penning-Rowsell, E., Li, Y., Shen, F., Chen, Y, LeQuense, T. (2014). Strategic flood management: ten 'golden rules' to guide a sound approach. International Journal of River Basin Management, DOI: 10.1080/15715124.2014.902378.

Sayers et al, (2015a) Climate Change Risk assessment 2017: Future flood risk in the UK. A report by Sayers and Partners LLP for the Climate Change Committee, London. https://www.theccc.org.uk/publication/sayersfor-the-asc-projections-of-future-flood-risk-in-the-uk/

Sayers et al, (2015b). Climate Change Risk assessment 2017: Future flood risk in the UK. Appendix F: The Future Flood Explorer - Overview Final. A report by Sayers and Partners LLP for the Climate Change Committee, London. https://www.theccc.org.uk/publication/sayers-for-the-ascprojections-of-future-flood-risk-in-the-uk/

Sayers et al, (2016). Flood resilience for disadvantaged areas. Submission to the National Resilience Review. A report by Sayers and Partners LLP for the Joseph Rowntree Foundation

Scottish Government, (2011). Delivering sustainable flood risk management.

http://www.gov.scot/Resource/Doc/351427/0117868.pdf

\section{Acknowledgements}

The advice and support of the Adaptation Sub-Committee as well as colleagues of Dave Thompson at the CCC, including Daniel Johns, Kathryn Humphrey and Manuela Di Mauro has been very much appreciated. The funding provided by the UK NERC via the Committee on Climate Change for the CCRA and the FoRUM (Grant 
NE/M008851/1 - in support of the validation of the national scale risk analysis for England) is gratefully acknowledged. The funding provided by Joseph Rowntree Foundation (Katharine Knox) in support of the analysis of disadvantage is also very much appreciated. 